\title{
Biologic Entity Part Anatomic Site Laterality Code
}

National Cancer Institute

\section{Source}

National Cancer Institute. Biologic Entity Part Anatomic Site Laterality Code. NCI

Thesaurus. Code C93747.

A coded value specifying the side of the body (or a paired organ) where the anatomic site

is in a biologic entity part. 